\title{
Total synthesis of all (-)-Agelastatin alkaloids
}

\author{
Mohammad Movassaghia, Dustin S. Siegel, and Sunkyu Han \\ aMassachusetts Institute of Technology, Department of Chemistry, 77 Massachusetts Avenue \\ 18-292, Cambridge, MA 02139-4307, USA; movassag@mit.edu
}

\begin{abstract}
The pyrrole-imidazole family of marine alkaloids, derived from linear clathrodin-like precursors, constitutes a diverse array of structurally complex natural products. The bioactive agelastatins are members of this family that possess a tetracyclic molecular framework incorporating C4-C8 and $\mathrm{C} 7-\mathrm{N} 12$ bond connectivities. We provide a hypothesis for the formation of the unique agelastatin architecture that maximally exploits the intrinsic chemistry of plausible biosynthetic precursors. We report the concise enantioselective total syntheses of all known agelastatin alkaloids including the first total syntheses of agelastatins C, D, E, and F. Our gram-scale chemical synthesis of agelastatin $\mathrm{A}$ was inspired by our hypothesis for the biogenesis of the cyclopentane $\mathrm{C}$-ring and required the development of new transformations including an imidazolone-forming annulation reaction and a carbohydroxylative trapping of imidazolones.
\end{abstract}

\section{Introduction}

The agelastatin alkaloids constitute an intriguing subset of the diverse pyrrole-imidazole family of marine alkaloids that are likely derived from linear biogenetic precursors such as clathrodin (7), ${ }^{1}$ hymenidin (8), ${ }^{2}$ and oroidin (9, Figure 1). $3^{, 4}$ (-)-Agelastatins A (1) and B (2) were first isolated from the Coral Sea sponge Agelas dendromorpha by Pietra in 1993 who successfully identified and chemically studied their unique tetracyclic structures. $5^{-8} \mathrm{In}$ 1998, Molinski isolated (-)-Agelastatins C (3) and D (4) from Cymbastela sp. native to the Indian Ocean. ${ }^{9}$ Recently, Al-Mourabit has reported the isolation of (-)-Agelastatins E (5) and $\mathrm{F}(\mathbf{6})$ from the New Caledonian sponge Agelas dendromorpha. ${ }^{10}(-)$-Agelastatin A (1) exhibits significant antitumor activity and inhibits osteopontin-mediated neoplastic transformation and metastasis in addition to slowing cancer cell proliferation by causing cells to accumulate in the $\mathrm{G}_{2}$ phase of the cell cycle.11,12 (-)-Agelastatin A (1) also exhibits toxicity towards arthropods, ${ }^{9}$ and selectively inhibits the glycogen synthase kinase-3 $\beta$, which is a potential target for the treatment of Alzheimer's disease and bipolar disorder. ${ }^{13,14}$

These properties have prompted considerable efforts toward the total synthesis of agelastatin A (1), resulting in inventive syntheses from 10 different research groups. In 1999, Weinreb completed the first total synthesis of agelastatin A (1) employing a key $\mathrm{N}$-sulfinyl dienophile hetero-Diels-Alder reaction. 15,16 Feldman reported the first enantioselective syntheses of (-)-Agelastatin A (1) and (-)-Agelastatin B (2) using an alkylidenecarbene $\mathrm{C}-\mathrm{H}$ insertion reaction. 17, 18 While Hale applied aziridine opening chemistry to the synthesis of (-)-1,19,20 Davis utilized ring-closing metathesis and $N$-sulfinyl imine based methodologies to access (-)-Agelastatin A (1).21,22 Sequential palladium-catalyzed asymmetric allylic alkylation reactions were key to Trost's concise total synthesis of (+)-1. ${ }^{23,24}$ Ichikawa's sigmatropic rearrangement of an allyl cyanate ${ }^{25}$ in addition to Wardrop and Chida's respective use of the

(c) The Royal Society of Chemistry [year]

Correspondence to: Mohammad Movassaghi. 
Overman rearrangement constituted additional successful approaches to 1.26,27 The interest in the field has continued with application of aziridination methodologies by Yoshimitsu, $28^{, 29}$ and most recently by Du Bois' elegant solution to (-)-1. ${ }^{30}$ Interestingly, all of these syntheses have in common an early introduction of the C-ring followed by further elaboration to afford the desired tetracyclic framework. Additionally, the reported syntheses of agelastatin A (1) do not specifically evaluate existing hypotheses for biogenesis of its intriguing molecular architecture. Furthermore, there are currently no total syntheses of agelastatins C (3), D (4), E (5), or F (6). Herein, we report the first biogenetically inspired and unified approach to all (-)-Agelastatins (1-6) using a concise synthetic strategy empowered by the inherent chemistry of potential biosynthetic intermediates.

The agelastatins are the only isolated pyrrole-imidazole alkaloids with C4-C8 and C7-N12 connectivities (Figure 1). Feeding studies by Kerr demonstrated that histidine and ornithine (or proline) are the amino acid precursors for related pyrrole-imidazole alkaloids. ${ }^{31}$ There are currently two reported biosynthetic hypotheses for the agelastatins, 5,32 and both suggest that the formation of the carbocyclic C-ring results from C8-nucleophilic trapping of a C4electrophile in a clathrodin derivative. Furthermore, these hypotheses suggest an early stage biosynthesis of the C-ring followed by B-ring formation and attribute stereochemical control to the action of putative enzymes.

\section{Results and discussion}

\section{Biosynthetic hypothesis and design plan for total synthesis}

The fascinating molecular architecture of the agelastatins and interest in evaluating our new hypothesis for the biogenetic origins of the C-ring involving cyclization with concomitant introduction of three stereocenters motivated the studies described here. We envisioned an advanced-stage biosynthetic sequence (Scheme 1) distinct from existing hypotheses that relies on: 1) reverse polarity in C-ring formation involving C4-nucleophilic trapping of a C8-electrophile for C-ring formation, 2) introduction of the C-ring after the B-ring formation, and 3) substrate directed stereochemical control and use of intrinsic chemistry that is perhaps enhanced by the action of biosynthetic enzymes. Our retrosynthetic factoring of (-)-Agelastatin A (1) inspired by our retrobiosynthetic analysis of $\mathbf{1}$ is illustrated in Scheme 1. Ionization of the C5-hydroxyl of $\mathbf{1}$ followed by the strategic disconnection of C4$\mathrm{C} 8$ reveals $\mathrm{N}$-acyliminium ion $\mathbf{1 7}$ and clears the carbocyclic C-ring along with three stereocenters. The mechanistic development of a transform ${ }^{33}$ linking 1 to 17 prompted consideration of a versatile precursor, pre-agelastatin A (16, Scheme 1). In the forward direction, our hypothesis asserts that pre-agelastatin A (16) may be ionized to the C8acyliminium ion 17, allowing a 5-exo-trig cyclization followed by $\mathrm{C} 5$-hydroxylation to secure the C4-, C5-, and C8-stereocenters in the final stage of the biosynthesis (Scheme 1, $\mathbf{1 6} \rightarrow \mathbf{1})$. We envisioned that pre-agelastatin A (16) would result from C2-hydrolysis and C8oxidation of the cyclooroidin analogue 14. Tricycle 14 would be formed by $\mathrm{C} 4$-protonation of linear precursor 11 followed by C7-trapping by the pyrrolyl-nitrogen (N12) via a 6-exotrig cyclization. ${ }^{34}$ Notably, this pathway suggests a link between the agelastatins and the natural product cyclooroidin (10, Figure 1), ${ }^{35}$ and is consistent with Lindel's reported acid promoted conversion of oroidin (9) to tricycle $\mathbf{1 0} .{ }^{36}$ Motivated by the potential direct conversion of pre-agelastatin A (16) to (-)-Agelastatin A (1), we targeted the related structure $O$-methyl-pre-agelastatin A (19) and envisioned its concise synthesis from readily available ${ }_{\mathrm{D}}$-aspartic acid derivative 22 (Scheme $1, \mathbf{2 2} \rightarrow \mathbf{1 9}$ ).

\section{Total synthesis of the agelastatin alkaloids}

Our convergent synthesis for the desired $O$-methyl-pre-agelastatin A (19) commenced with pyrrole (+)-22 (Scheme 2), accessible in one step from commercially available ${ }_{\mathrm{D}}$-aspartic 
acid dimethyl ester. ${ }^{37}$ Exposure of pyrrole (+)-22 to $N$-bromosuccinimide (NBS) in the presence of 2,6-di-tert-butyl-4-methylpyridine (DTBMP) afforded the bromopyrrole (+)-23 in $92 \%$ yield and $99 \%$ ee. Treatment of bromopyrrole $(+)-\mathbf{2 3}$ with chlorosulfonyl isocyanate afforded amide (+)-24 in $82 \%$ yield. Subsequently, addition of sodium borohydride followed by $p$-toluenesulfonic acid (TsOH) to a methanolic solution of (+)-24 generated bicycle $(+)-21$ as a single diastereomer in $90 \%$ yield and $99 \%$ ee on greater than 10 -gram scale. The conversion of (+)-24 to bicycle (+)-21 occurs via formation and immediate C8-reduction of the imide 25, preventing an undesired C7-epimerization. ${ }^{38}$ Identical B-ring formation with the desbromopyrrole derivative of $\mathbf{2 4}$ resulted in significant erosion of enantiopurity. This observation was consistent with our postulate that the $\mathrm{C} 7-\mathrm{H}$ bond would be forced to adopt a pseudo-equatorial conformation to minimize allylic strain between the C13-bromine and C6-methylene, which suppressed undesired C7-deprotonation. Interestingly, the use of pyrrole (+)-24, possessing the C13-bromine present in all known agelastatins, provided chemical reactivity beneficial to our synthetic strategy (vide infra).

We next aimed to develop a general strategy for the introduction of the imidazolone substructure present in the targeted pre-agelastatin $16 .{ }^{39}$ Initially, we focused on the direct addition of transmetallated derivatives of triazone $\mathbf{2 7}$ (Scheme 2, metal $=\mathrm{Li}, \mathrm{Mg}, \mathrm{Cu}, \mathrm{Ce}$, $\mathrm{Zn})$ to the bicyclic C5-ester (+)-21. Unfortunately, these attempts were plagued by either lack of reactivity, the formation of byproducts associated with metal-halogen exchange, double addition, or competing decomposition pathways. Furthermore, these metallated $40^{-42}$ triazone derivatives were generally unstable at temperatures above $0{ }^{\circ} \mathrm{C}$. Thus, the development of a new strategy for the union of a stable metallated triazone and ester (+)-21 as the prelude to introduction of the imidazolone was necessary.

We envisioned that the cross coupling of thioester derivatives $43^{-45}$ with stannylurea derivatives would represent a versatile synthesis of substituted imidazolones. Thioester (+)-26 was readily prepared in $92 \%$ yield through treatment of ester (+)-21 with trimethylaluminum and 4-methylbenzenethiol in dichloromethane (Scheme 2). The structure of (+)-26 was secured via X-ray crystallographic analysis, ${ }^{46}$ revealing the pseudo-equatorial $\mathrm{C} 7-\mathrm{H}$ bond. After extensive experimentation, we found that the union of thioester (+)-26 with the readily available triazone $2747^{-49}$ could be achieved efficiently in the presence of stoichiometric copper(I)-thiophene-2-carboxylate (CuTC) to give the ketone (+)-28 (96\%, $>5 \mathrm{~g}$-scale). Exposure of triazone ( + )-28 to methanolic hydrogen chloride unraveled the ketourea 20, which upon spontaneous condensative cyclization50,51 provided the desired $(+)-O-$ methyl-pre-agelastatin A (19) in 89\% yield with $99 \%$ ee (Scheme 2). The structure of (+)-19 was secured via X-ray crystallographic analysis, and its thermal ellipsoid representation illustrates that the $\mathrm{C} 7$-methylimidazolone and $\mathrm{C} 8$-methoxy group reside in a pseudo-diaxial conformation (C6-C7-C8-O8' dihedral angle of $\left.173^{\circ}\right) .{ }^{46}$

With (+)-O-methyl-pre-agelastatin A (19) in hand, we proceeded to evaluate our hypothesis for C-ring biogenesis and rapid introduction of the C4-, C5-, and C8-stereocenters. Gratifyingly, heating an aqueous solution of (+)-19 with methanesulfonic acid provided (-)Agelastatin A (1, Scheme 2) as the major product along with (-)-4,5-di-epi-agelastatin A (structure not illustrated) as the minor stereoisomer (2:1). Monitoring of this reaction by ${ }^{1} \mathrm{H}$ NMR revealed that (-)-4,5-di-epi-agelastatin A is the kinetic product, which equilibrates to the thermodynamically favored desired product (-)-Agelastatin A (1), likely via intermediacy of tetracycle (-)-30. Analysis of the rate of solvolysis of each isomer illustrated that the C5-hydroxyl of (-)-4,5-di-epi-agelastatin A ionizes significantly faster than the corresponding C5-hydroxyl of (-)-Agelastatin A (1). In the event, upon complete consumption of pre-agelastatin A (16), simple exposure of the reaction mixture to methanol efficiently converted (-)-4,5-di-epi-agelastatin A to (-)-O-methyl-di-epi-agelastatin A (29), enabling facile separation of (-)-1 and (-)-29 (Scheme 2). Under preparative conditions, our 
putative biomimetic cyclization of (+)-19 afforded (-)-Agelastatin A (1) in 49\% yield (1.4 g, 99\% ee) along with (-)-O-methyl-di-epi-agelastatin A (29) in $22 \%$ yield. This constitutes a total chemical synthesis of (-)-Agelastatin A (1) in eight steps for the longest linear sequence from commercially available starting material with $22 \%$ overall yield. Furthermore, resubmission of (-)-29 to the above protocol afforded (-)-Agelastatin A (1) in $66 \%$ yield along with recovered (-)-29 (30\%) post equilibration. The structure of (-)-1 was secured through X-ray crystallographic analysis (Scheme 2) ${ }^{46}$ It should be noted that this 5(enolendo)-exo-trig52 type of cyclization with an acyliminium ion is a rare and challenging reaction as evidenced by the paucity of relevant examples in the literature.53, ${ }^{54}$ Importantly, the versatility of our new imidazolone annulation allows for the union of thioester (+)-26 and the simple stannylurea derivative $33\left({ }^{c} \mathrm{Hx}_{3} \mathrm{SnCH}_{2} \mathrm{NH}(\mathrm{CO}) \mathrm{NHMe}\right)$ to afford (+)-Omethyl-pre-agelastatin A (19) without isolation of any intermediates, providing the shortest total synthesis of (-)-Agelastatin A (1, 7-steps, Scheme 2) to date.

Under optimal conditions, treatment of (-)-Agelastatin A (1) with NBS and DTBMP in a water-tetrahydrofuran solvent mixture afforded (-)-Agelastatin B (2) in 84\% yield. Interestingly, X-ray crystallographic analysis of (-)-Agelastatin B (2) revealed that its Cring conformation is distinct from that of (-)-Agelastatin $\mathrm{A}(\mathbf{1})$ as highlighted by the $25^{\circ}$ and $31^{\circ}$ difference in the C5-C4-C8-N9 and N1-C5-C4-C8 dihedral angles, respectively. ${ }^{46}$

Importantly, (-)-O-methyl-di-epi-agelastatin A (29) served as a versatile precursor for the synthesis of (-)-Agelastatin C (3, Scheme 2). Heating a solution of (-)-O-methyl-di-epiagelastatin A (29) in pyridine afforded (-)-dehydroagelastatin A (30, Scheme 2) in $99 \%$ yield. ${ }^{55}$ As anticipated, treatment of $\mathbf{3 0}$ with dimethyldioxirane (DMDO) gave (-)-di-epiagelastatin C $(\mathbf{3 1}, 98 \%)$ via oxidation on the convex face. Significantly, heating an aqueous solution of (-)-di-epi-agelastatin C (31) with BrØnsted acid slowly afforded (-)-Agelastatin $\mathrm{C}(\mathbf{3}, 41 \%)$ along with recovered $\mathbf{3 1}(42 \%)$. We propose that this equilibration occurs via the intermediate 32 consistent with our observations of deuterium incorporation at the C6methylene when using deuterium oxide as solvent. ${ }^{56}$

Our new imidazolone annulation methodology proved most effective for accessing the desired pre-agelastatin D intermediate for the first synthesis of (-)-Agelastatin D $(\mathbf{4}$, Scheme 3 ). Under our optimized conditions, treatment of thioester (+)-26 with stannylurea $\mathbf{3 4}$ and $\mathrm{CuTC}$ followed by exposure to methanolic hydrogen chloride afforded (+)-O-methyl-preagelastatin $\mathrm{D}(\mathbf{3 5})$ in $62 \%$ yield. Despite the attenuated C4-nucleophilicity of (+)-O-methylpre-agelastatin D (35) compared to (+)-O-methyl-pre-agelastatin A (19) in polar-protic solvents, ${ }^{57}$ application of our key cyclization protocol as described above indeed provided the desired (-)-Agelastatin D (4) in $26 \%$ yield along with (-)-O-methyl-di-epi-agelastatin D $(36,9 \%) .{ }^{58}$ The structure of (-)-Agelastatin D (4), secured through X-ray crystallographic analysis, demonstrated a C-ring conformation similar to $(-)-1 .{ }^{46}$ Despite the success of this putative biomimetic cyclization, the greater propensity of $\mathbf{3 5}$ to undergo competing reactions was evident by formation of the C6-C7 bond-cleavage product $\mathbf{3 8}(20 \%)^{59}$ and the tetracyclic byproduct $\mathbf{4 0}(20 \%)$. Formation of tetracycle $\mathbf{4 0}$ is consistent with a competing loss of methanol to afford pyrrolopyrazinone $\mathbf{3 9}$, an observed intermediate, that prevents the desired C-ring formation and permits $\mathrm{C} 13$ to engage the imidazolone. ${ }^{60}$ The observed lower efficiency of the desired cyclization with $\mathbf{3 5}$ compared to $\mathbf{1 9}$ echoes the scarcity of natural (-)-Agelastatin D (4) compared to other $N$-methyl agelastatin alkaloids. ${ }^{9,10,61}$

Furthermore, we have accessed the structures of the two newly isolated (-)-Agelastatins $\mathrm{E}$ (5) and F (6) by their direct synthesis from (-)-Agelastatin A (1) and D (4), respectively (Scheme 4). Heating a methanolic solution of (-)-Agelastatin A (1) with BrØnsted acid at 65 ${ }^{\circ} \mathrm{C}$ for $2 \mathrm{~h}$ afforded (-)-Agelastatin E (5) in 96\% yield (Scheme 4). ${ }^{7}$ A synthetic sample of $(-)$-Agelastatin $\mathrm{F}(\mathbf{6})$ was generated in $86 \%$ yield by bromination of (-)-Agelastatin D (4) 
under the optimal conditions described above for the synthesis of (-)-Agelastatin B (2), thereby confirming its molecular structure.

Our biosynthetically inspired strategy for the advanced stage C-ring formation drew on the intrinsic chemistry of our proposed pre-agelastatin intermediates for rapid generation of molecular complexity, enabling a unified approach to all known agelastatin alkaloids. Collectively, our observations hint at a plausible sequence of events for the biogenesis of the alkaloids 1-6 (Scheme 1). For example, the C13-bromopyrrole and the imidazolinone substructures (present in all agelastatins) were critical in the successful C-ring cyclization. Treatment of the des-bromo derivative $\mathbf{4 1}$ under the optimized cyclization conditions did not afford the desired C-ring due to a more facile conversion to pyrrolopyrazinone $\mathbf{4 2}(57 \%$, Scheme 5), ${ }^{62}$ suggesting a beneficial role for the allylic strain between the C13-bromine and C6-methylene to restrict the $\mathrm{C} 7$-methine in a pseudo-equatorial conformation during the key cyclization event.

Additionally, the aminoimidazole $\mathbf{4 3}$ failed to undergo the desired cyclization reaction due to a more competitive pyrrolopyrazinone $\mathbf{4 4}$ formation (92\%, Scheme 5), an observation we attribute to the greater propensity of the aminoimidazolone substructure to remain protonated and thus less nucleophilic under the reaction conditions.

Consequently, we suggest a higher probability for biosynthetic introduction of the C13bromopyrrole and imidazolone substructures prior to C-ring formation. Moreover, our observations regarding the higher predisposition for the pre-agelastatin A derivative (+)-19, to undergo $\mathrm{C}$-ring formation as compared to the desmethyl derivative (+)-35 may suggest predominant N1-methylation prior to $\mathrm{C}$-ring cyclization in the biogenesis of the agelastatins. The stereochemical outcome for the key C-ring cyclization is controlled by the C7-methine to secure the desired thermodynamically favored C4-, C5-, and C8-stereocenters. Specifically, the C5-center is controlled by the C4-stereochemistry to give a cis-fused CDring system upon hydroxylation. It is conceivable that putative agelastatin biosynthetic enzymes have evolved to enhance the innate stereoselectivity of compounds related to those utilized in our synthesis. ${ }^{63}$ While our total syntheses of alkaloids 1-6 do not confirm our hypothesis for their biogenesis, it is gratifying to have chemical validation for our proposed mode and timing of bond and ring formations in the biosynthesis of these alkaloids.

\section{Conclusions}

We have completed the total syntheses of all known agelastatin alkaloids (1-6) through a unified strategy inspired by our hypothesis for their biogenesis. Key features of our syntheses include: 1) the concise multi-gram scale enantioselective synthesis of our proposed "pre-agelastatin" derivatives, 2) the use of the bromopyrrole substructure to suppress C7-deprotonation, 3) a versatile synthesis of imidazolone derivatives via a new $[4+1]$ annulation strategy, 4) the validation of our bioinspired 5-exo-trig advanced stage Cring formation, and 5) utilization of the intrinsic chemistry of plausible biosynthetic intermediates for rapid generation of molecular complexity. The overall efficiency of our strategy is highlighted by our 1.4 gram batch enantioselective synthesis of (-)-Agelastatin A (1). With this most concise total chemical synthetic access to all natural agelastatin alkaloids and related derivatives, studies aimed at probing their chemical and biological mode of action are ongoing and will be the subject of forthcoming reports.

\section{Supplementary Material}

Refer to Web version on PubMed Central for supplementary material. 


\section{Acknowledgments}

We are grateful for financial support by NIH-NIGMS (GM074825). We thank Justin Kim for X-ray crystallographic analysis of (-)-1, (-)-2, (-)-4, (+)-19, (+)-21, and (+)-26. M.M. is an Alfred P. Sloan Research Fellow. We thank Amgen, AstraZeneca, Bristol-Myers Squibb, and DuPont for additional financial support.

\section{Notes and references}

1. Morales JJ, Rodriguez AD. J. Nat. Prod 1991;54:629-631.

2. Kobayashi J, Ohizumi H, Hirata Y. Experientia 1986;42:1176-1177. [PubMed: 3770140]

3. Forenza S, Minale L, Riccio R, Fattorusso E. J. Chem. Soc., Chem. Commun 1971:1129-1130.

4. Garcia EE, Benjamin LE, Fryer RI. J. Chem. Soc., Chem. Commun 1973:78-79.

5. D'Ambrosio M, Guerriero A, Debitus C, Ribes O, Pusset J, Leroy S, Pietra F. J. Chem. Soc., Chem. Commun 1993:1305-1306.

6. D’Ambrosio M, Guerriero A, Chiasera G, Pietra F. Helv. Chim. Acta 1994;7:1895-1902.

7. D’Ambrosio M, Guerriero A, Ripamonti M, Debitus C, Waikedre J, Pietra F. Helv. Chim. Acta 1996;79:727-735.

8. For an additional isolation report and X-ray crystallographic analysis of (-)-1, see: Pettit GR, Ducki S, Herald DL, Doubek DL, Schmidt JM, Chapuis J. Oncol. Res 2005;15:11-20. [PubMed: 15839302]

9. Hong TW, Jímenez DR, Molinski TF. J. Nat. Prod 1998;61:158-161. [PubMed: 9461668]

10. Tilvi S, Moriou C, Martin M, Gallard J, Sorres J, Patel K, Petek S, Debitus C, Ermolenko L, AlMourabit A. J. Nat. Prod 2010;73:720-723. [PubMed: 20166736]

11. Mason CK, McFarlane S, Johnston PG, Crowe P, Erwin PJ, Domostoj MM, Campbell FC, Manaviazar S, Hale KJ, El-Tanani M. Mol. Cancer Ther 2008;7:548-558. [PubMed: 18347142]

12. Kapoor S. J. Cancer Res. Clin. Oncol 2008;134:927-928. [PubMed: 18491136]

13. Meijer L, Thunnissen A, White AW, Garnier M, Nikolic M, Tsai L, Walter J, Cleverley KE, Salinas PC, Wu Y, Biernat J, Mandelkow E, Kim S, Pettit GR. Chem. Biol 2000;7:51-63. [PubMed: 10662688]

14. Hale, KJ.; Domostoj, MM.; El-Tanani, M.; Campbell, FC.; Mason, CK. Strategies and Tactics in Organic Synthesis. Harmata, M., editor. Vol. vol. 6. London: Elsevier Academic Press; 2005. p. 352-394.

15. Anderson GT, Chase CE, Koh Y, Stien D, Weinreb SM. J. Org. Chem 1998;63:7594-7595.

16. Stien D, Anderson GT, Chase CE, Koh Y, Weinreb SM. J. Am. Chem. Soc 1999;121:9574-9579.

17. Feldman KS, Saunders JC. J. Am. Chem. Soc 2002;124:9060-9061. [PubMed: 12149004]

18. Feldman KS, Saunders JC, Wrobleski ML. J. Org. Chem 2002;67:7096-7109. [PubMed: 12354005]

19. Hale KJ, Domostoj MM, Tocher DA, Irving E, Scheinmann F. Org. Lett 2003;5:2927-2930. [PubMed: 12889910]

20. Domostoj MM, Irving E, Scheinmann F, Hale KJ. Org. Lett 2004;6:2615-2618. [PubMed: 15255704]

21. Davis FA, Deng J. Org. Lett 2005;7:621-623. [PubMed: 15704909]

22. Davis FA, Zhang Y, Qiu H. Synth. Comm 2009;39:1914-1919.

23. Trost BM, Dong G. J. Am. Chem. Soc 2006;128:6054-6055. [PubMed: 16669672]

24. Trost BM, Dong G. Chem.-Eur. J 2009;15:6910-6919.

25. Ichikawa Y, Yamaoka T, Nakano K, Kotsuki H. Org. Lett 2007;9:2989-2992. [PubMed: 17602639]

26. Dickson PD, Wardrop DJ. Org. Lett 2009;11:1341-1344. [PubMed: 19228041]

27. Hama N, Matsuda T, Sato T, Chida N. Org. Lett 2009;11:2687-2690. [PubMed: 19449885]

28. Yoshimitsu T, Ino T, Tanaka T. Org. Lett 2008;10:5457-5460. [PubMed: 19006318]

29. Yoshimitsu T, Ino T, Futamura N, Kamon T, Tanaka T. Org. Lett 2009;11:3402-3405. [PubMed: 19588910] 
30. When PM, Du Bois J. Angew. Chem., Int. Ed. Engl 2009;48:3802-3805. [PubMed: 19378315]

31. Andrade P, Willoughby R, Pomponi SA, Kerr RG. Tetrahedron Lett 1999;40:4775-4778.

32. Al-Mourabit A, Potier P. Eur. J. Org. Chem 2001:237-243.

33. Corey, EJ.; Cheng, X. The Logic of Chemical Synthesis. John Wiley \& Sons; 1995. p. 1-16.

34. Alternative timing for the N1-methylation has been considered and may occur at any point up to pre-agelastatin A (16) for our biosynthetic hypothesis for (-)-1.

35. Fattorusso E, Taglialatela-Scafati O. Tetrahedron Lett 2000;41:9917-9922.

36. Pöerlein C, Breckle G, Lindel T. Org. Lett 2006;8:819-821. [PubMed: 16494449]

37. Pyrrole (+)-22 is synthesized in one step from commercial $\mathrm{D}$-aspartic acid dimethylester in $84 \%$ (99\% ee) on >15-gram scale. See the supporting information for details. Also see: Jefford CW, de Villedon de Naide F, Sienkiewicz K. Tetrahedron: Asymmetry 1996;7:1069-1076.

38. Treatment of (+)-24 with methanol- $d_{4}$ for $2 \mathrm{~h}$ resulted in the formation of imide 25 in $99 \%$ yield and $99 \%$ deuterium incorporation at $\mathrm{C} 7$ with complete loss of optical activity.

39. Zav'yalov SI, Ezhova GI, Kravchenko NE, Kulikova LB, Dorofeeva OV, Rumyantseva EE, Zavozin AG. Phar. Chem. J 2004;38:256-260.

40. Hassel T, Seebach D. Helv. Chim. Acta 1978;61:2237-2240.

41. Beak P, Zajdel WJ, Reitz DB. Chem. Rev 1984;84:471-523.

42. Pearson WH, Lindbeck AC, Kampf JW. J. Am. Chem. Soc 1993;115:2622-2636.

43. Wittenberg R, Srogl J, Egi M, Liebeskind LS. Org. Lett 2003;5:3033-3035. [PubMed: 12916974]

44. For a review, see: Fukuyama T, Tokuyama H. Aldrichimica Acta 2004;37:87-96.

45. For a recent review, see: Prokopcová H, Kappe CO. Angew. Chem., Int. Ed. Engl 2009;48:22762286. [PubMed: 19067446]

46. Structural parameters for (-)-1, (-)-2, (-)-4, (+)-19, (+)-21, and (+)-26 are freely available from the Cambridge Crystallographic Data Center under CCDC-775302, CCDC-775303,

CCDC-775304, CCDC-775306, CCDC-775305, and CCDC-775307, respectively.

47. Stannyltriazone 27 was prepared in two steps from commercial material on $>10$-gram scale via lithiation of the corresponding triazone followed by trapping with tricyclohexylstannyl chloride.

48. Knapp S, Hale JJ, Bastos M, Gibson FS. Tetrahedron Lett 1990;31:2109-2112.

49. Knight SD, Overman LE, Pairaudeau G. J. Am. Chem. Soc 115:9293-9294.

50. Marckwald W. Chem. Ber 1892;25:2354-2373.

51. Duschinsky R, Dolan LA. J. Am. Chem. Soc 1946;68:2350-2355. [PubMed: 21002238]

52. Baldwin JE, Lusch MJ. Tetrahedron 1982;38:2939-2947.

53. Gramain JC, Remuson R. Heterocycles 1989;29:1263-1273.

54. Heaney H, Taha MO. Tetrahedron Lett 1998;39:3341-3344.

55 . For a previously described semi-synthesis of (-)-30 from (-)-5, see ref 7. Notably, we observed that $(-)-29$ undergoes dehydration at a faster rater than $(-)-5$.

56. Treatment of either (-)-di-epi-agelastatin $\mathrm{C} \mathrm{(31)}$ or (-)-Agelastatin $\mathrm{C}(\mathbf{3})$ with $\mathrm{MeSO}_{3} \mathrm{H}$ (10 equiv) in $\mathrm{D}_{2} \mathrm{O}$ at $100{ }^{\circ} \mathrm{C}$ for $3 \mathrm{~d}$, afforded a $1: 1$ equilibrium mixture of (-)-di-epi-agelastatin $\mathrm{C} \mathrm{(31)}$ and (-)-Agelastatin C (3) with quantitative deuterium incorporation at the C6-methylene as indicated by ${ }^{1} \mathrm{H}$ NMR analysis. See supporting information for details.

57. Direct comparison of the rates of deuterium incorporation between $(+)-O$-methyl-pre-agelastatin A (19) and (+)-O-methyl-pre-agelastatin D (35) revealed that (+)-19 incorporates deuterium at the C4-position 10 times faster than (+)-35.

58. Resubmission of (-)-O-methyl-di-epi-agelastatin $\mathrm{D}(36)$ to $\mathrm{MeSO}_{3} \mathrm{H}$ in $\mathrm{H}_{2} \mathrm{O}$ at reflux for $25 \mathrm{~h}$ afforded (-)-Agelastatin D (4) in 68\% yield.

59. C6-C7 bond fragmentation, requiring C5-C6 $\pi$-bond formation, is likely facilitated by diminished allylic strain imposed by the N1-H intermediate 36 compared to N1-Me derivative 17.

60. ${ }^{1} \mathrm{H}$ NMR monitoring of this reaction revealed the formation and slow consumption of $\mathbf{3 9}$. At lower temperature $\left(60^{\circ} \mathrm{C}\right), 39$ was recovered from the reaction mixture; its resubmission to the cyclization conditions afforded $\mathbf{4 0}$ in $24 \%$ yield.

61. Neither the optical rotation nor the ${ }^{13} \mathrm{C}$ NMR spectrum of agelastatin D was obtained in the original isolation report as it was a minor component. 
62. The C8-hydroxy derivative of $\mathbf{4 1}$ accounted for approximately $20 \%$ of the mass balance after 20 min. Prolonged exposure of $\mathbf{4 1}$, the C8-hydroxy derivative of $\mathbf{4 1}$, or $\mathbf{4 2}$ to the reaction conditions did not afford the desired cyclization.

63. The opposite C7-stereochemistry of (-)-cyclooroidin (10) compared to that of the agelastatins entreats the possibility that downstream biosynthetic enzymes may preferentially bind and consume derivatives of ent-cyclooroidin for the synthesis of the agelastatins. 


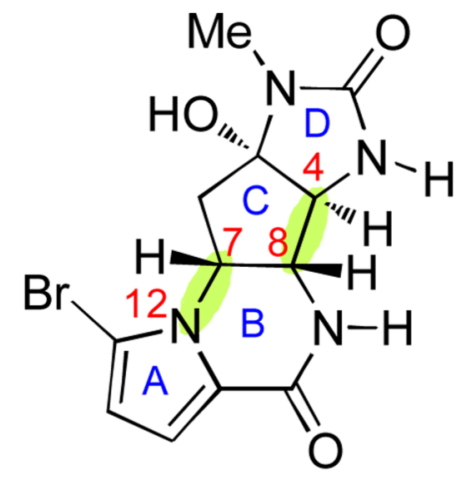

(-)-agelastatin A (1)<smiles>O=C1N[C@@H]2CN(O)C(=O)N[C@H]2n2c(Br)ccc21</smiles>

(-)-agelastatin D (4)

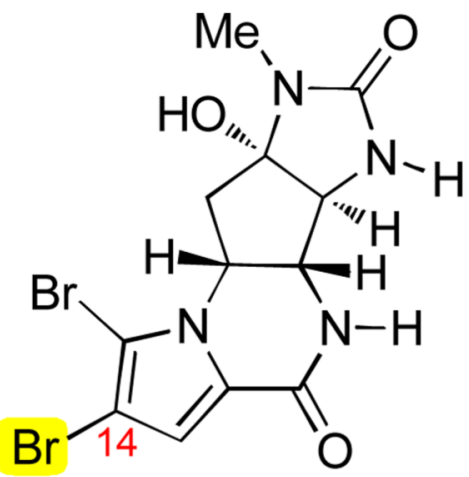

(-)-agelastatin B (2)<smiles></smiles>

(-)-agelastatin E (5)

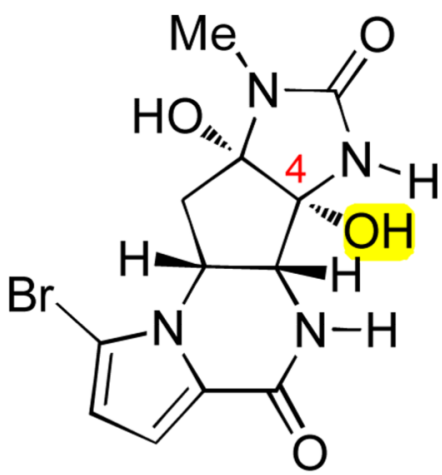

(-)-agelastatin C (3)

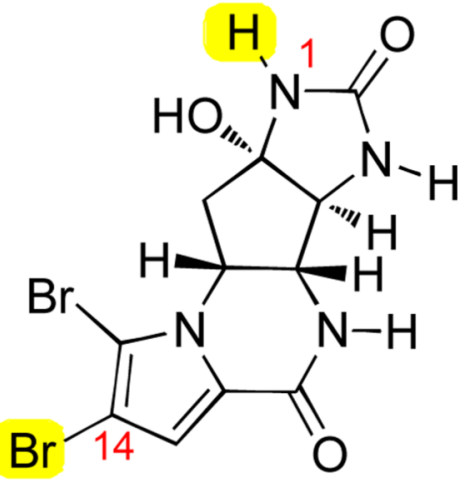

(-)-agelastatin F (6)<smiles>O=C1NCCn2c1cc(Br)c2Br</smiles>

(-)-cyclooroidin (10)

Fig. 1.

The molecular structures of all agelastatin alkaloids (1-6) and biogenetically related naturally occurring simpler pyrrole-imidazole alkaloids (7-10). 


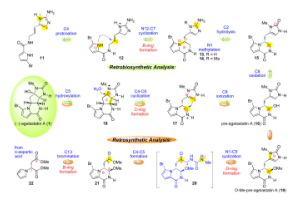

Scheme 1.

Our retrosynthetic analysis of (-)-Agelastatin A (1) inspired by our biosynthetic hypothesis that involves intermediacy of pre-agelastatin A (16) in a final stage formation of the C-ring and rapid introduction of the C4-, C5-, and C8-stereochemistry $(\mathbf{1 6} \rightarrow \mathbf{1})$. 

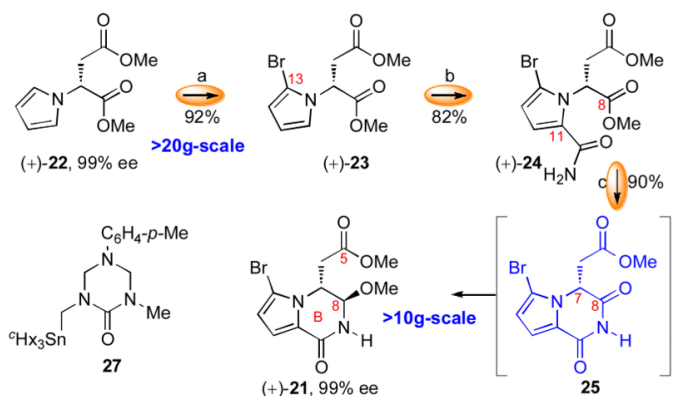

thermal elipsoid

representation
of $(+)-26$

d. $92 \%$

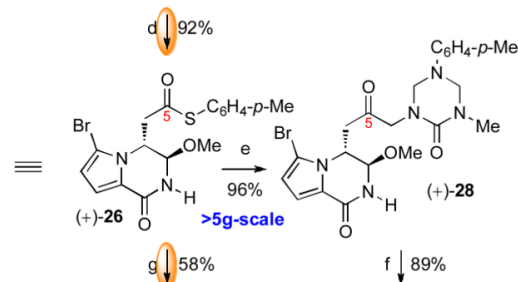

thermal ellipsoid

representation
of $(+)-19$

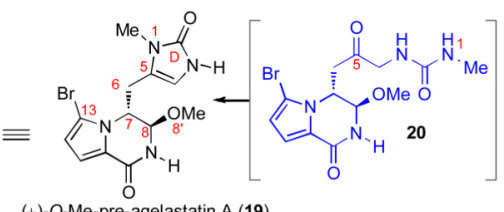

(+)-O-Me-pre-agelastatin A (19)

$n D_{71 \%}>1 \mathrm{~g}$-scale

thermal ellipsoid
representation
of $(-)-1$

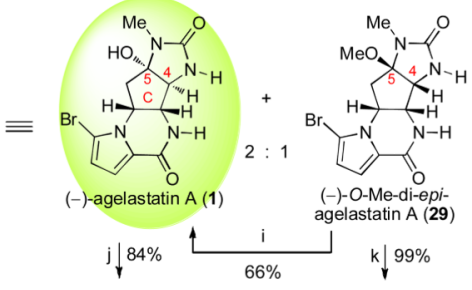

thermal ellipsoid
representation

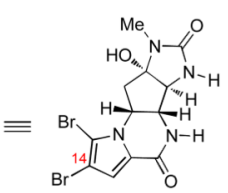

$(-)$-agelastatin B (2)

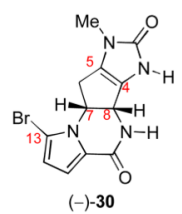

1 | $98 \%$

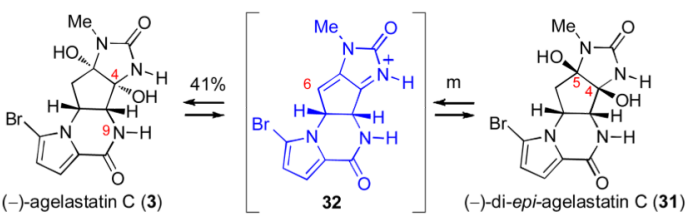

Scheme 2.

Gram-scale enantioselective total synthesis of (-)-Agelastatin A (1) and elaboration to (-)Agelastatin B (2) and (-)-Agelastatin C (3). Reagents and conditions: (a) NBS, DTBMP, THF (92\%); (b) $\mathrm{ClSO}_{2} \mathrm{NCO}, \mathrm{MeCN}, 0{ }^{\circ} \mathrm{C} ; \mathrm{Na}\left(\mathrm{Hg}\right.$ ), $\mathrm{NaH}_{2} \mathrm{PO}_{4}$ (82\%); (c) $\mathrm{NaBH}_{4} \mathrm{MeOH}, 0$ ${ }^{\circ} \mathrm{C}$; $\mathrm{TsOH} \bullet \mathrm{H}_{2} \mathrm{O}, 23{ }^{\circ} \mathrm{C}(90 \%)$; (d) $\mathrm{HSC}_{6} \mathrm{H}_{4}-p-\mathrm{Me}, \mathrm{AlMe}_{3}, \mathrm{CH}_{2} \mathrm{Cl}_{2}, 0{ }^{\circ} \mathrm{C}(92 \%)$; (e) 27, CuTC, THF, $50{ }^{\circ} \mathrm{C}(96 \%)$; (f) $\mathrm{HCl}(0.5 \mathrm{~N}), \mathrm{MeOH}, 65^{\circ} \mathrm{C}(89 \%)$;

(g) ${ }^{\mathrm{C}} \mathrm{Hx}_{3} \mathrm{SnCH}_{2} \mathrm{NH}(\mathrm{CO}) \mathrm{NHMe}(\mathbf{3 3}), \mathrm{CuTC}, \mathrm{THF}, 50{ }^{\circ} \mathrm{C}$; $\mathrm{HCl}(0.5 \mathrm{~N}), \mathrm{MeOH}, 23{ }^{\circ} \mathrm{C}(58 \%)$; (h) $\mathrm{MeSO}_{3} \mathrm{H}, \mathrm{H}_{2} \mathrm{O}, 100{ }^{\circ} \mathrm{C}$; $\mathrm{MeOH}(71 \%(2: 1,(-)-\mathbf{1}:(-)-29))$; (i) $\mathrm{MeSO}_{3} \mathrm{H}, \mathrm{H}_{2} \mathrm{O}, 100{ }^{\circ} \mathrm{C}$; $\mathrm{MeOH}\left(66 \%\right.$ of (-)-1, and 30\% of recovered (-)-29); (j) NBS, DTBMP, THF, $\mathrm{H}_{2} \mathrm{O}, 0{ }^{\circ} \mathrm{C}$ (84\%); (k) pyr., $115^{\circ} \mathrm{C}$ (99\%); (l) DMDO, acetone, $\mathrm{H}_{2} \mathrm{O}$ (98\%); (m) Amberlyst 15, $\mathrm{H}_{2} \mathrm{O}$, 
$100{ }^{\circ} \mathrm{C}, 5 \mathrm{~d}(41 \%$ of $(-)-3$, and $42 \%$ of recovered (-)-31); NBS $=N$-bromosuccinimide, DTBMP $=2,6$-di- ${ }^{-}$butyl-4-methylpyridine, $\mathrm{TsOH}=p$-toluenesulfonic acid, $\mathrm{CuTC}=$ copper(I)-thiophene-2-carboxylate, $\mathrm{DMDO}=$ dimethyldioxirane, pyr. $=$ pyridine. 
<smiles>CCCCCCSC(=O)C[C@H]1[C@H](OC)[C@@H](OC)NC(=O)c2ccc(Br)n21</smiles>

$(+)-26$ $a, b$

$\underset{62 \%}{\longrightarrow}$

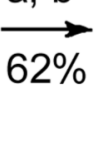

(+)-O-Me-pre-agelastatin D (35)<smiles>CO[C@H]1NC(=O)c2ccc(Br)n2[C@@H](Cc2c[nH]c(=O)[nH]2)[C@@H]1O[GeH3]</smiles><smiles>O=C1N[C@H]2[C@H]3NC(=O)c4ccc(Br)n4[C@@H](O)[C@H]3C[C@]2(O)N1</smiles>

(-)-agelastatin D (4)

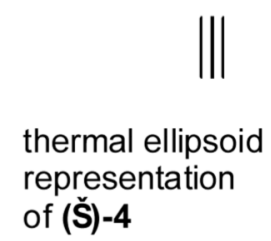<smiles>CO[C@]12C[C@H](C)n3c(Br)ccc3C(=O)N[C@H]1[C@H]1NC(=O)N[C@H]12</smiles>

(-)-O-Me-di-epiagelastatin $\mathrm{D}(\mathbf{3 7})$

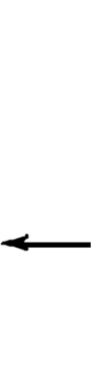<smiles></smiles>

$\downarrow c$<smiles>O=c1[nH]ccn2c(Br)ccc12</smiles>

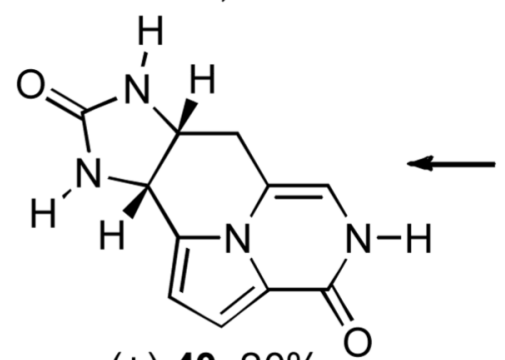

$( \pm)-40,20 \%$<smiles>O=c1[nH]cncc1Cc1c[nH]c(=O)c2ccc(Br)n12</smiles>

Scheme 3.

Total synthesis of (-)-Agelastatin D (4). Reagents and conditions: (a) CuTC, THF, $50{ }^{\circ} \mathrm{C}$; (b) $\mathrm{HCl}(0.5 \mathrm{~N}), \mathrm{MeOH}, 23{ }^{\circ} \mathrm{C}\left(62 \%\right.$ (2-steps)); (c) $\mathrm{MeSO}_{3} \mathrm{H}, \mathrm{H}_{2} \mathrm{O}, 100{ }^{\circ} \mathrm{C} ; \mathrm{HCl}, \mathrm{MeOH}$ (26\% (-)-4, $9 \%(-)-37,20 \%$ 38, 20\% (士)-40); CuTC = copper(I)-thiophene-2-carboxylate. 


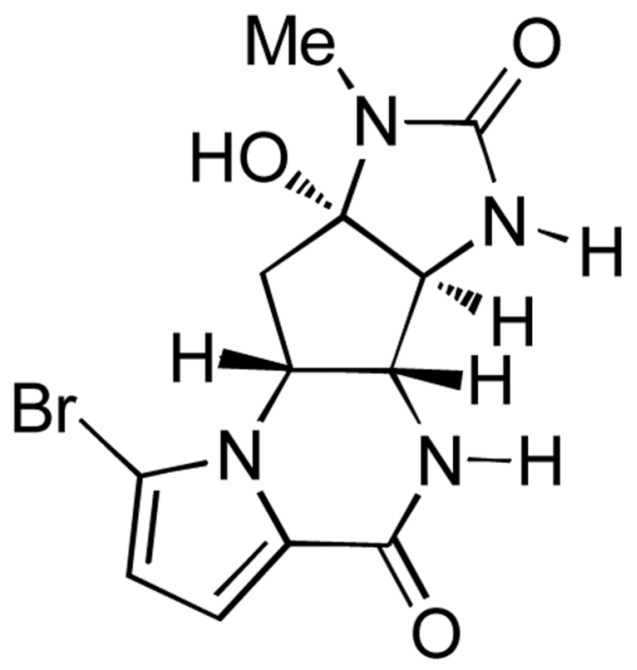

(-)-agelastatin A (1)

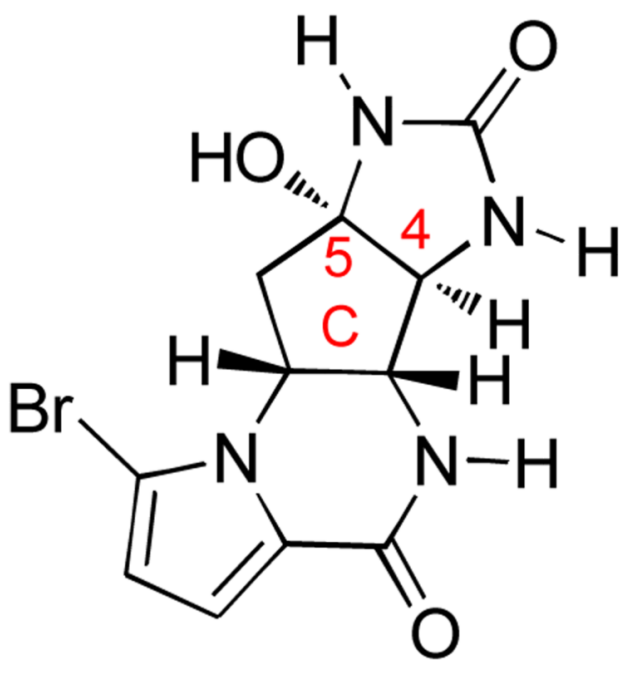

(-)-agelastatin D (4)

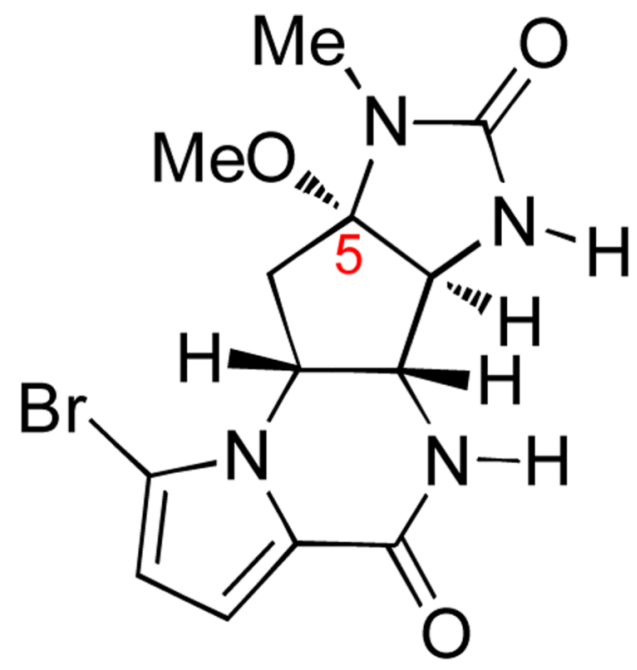

(-)-agelastatin E (5)

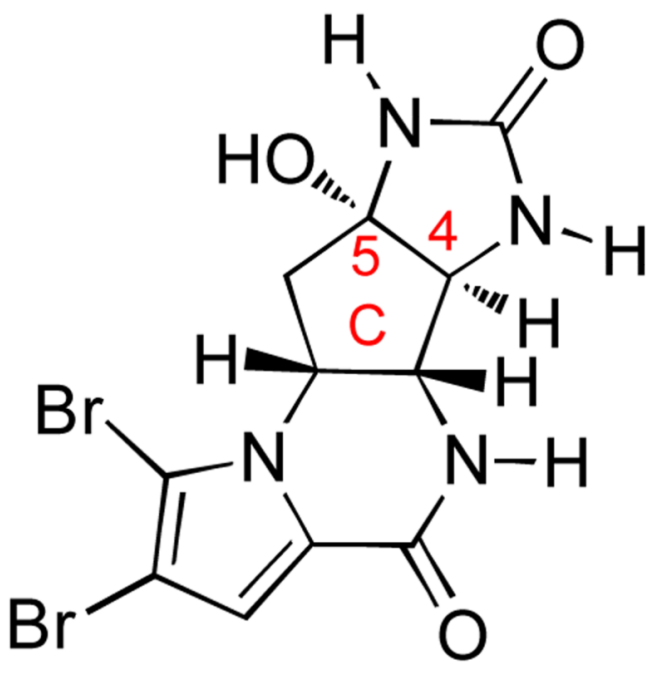

$(-)$-agelastatin $\mathrm{F}(6)$

Scheme 4.

Total synthesis of (-)-Agelastatin E (5) and (-)-Agelastatin F (6). Reagents and conditions:

(a) Amberlyst 15, MeOH, $65^{\circ} \mathrm{C}(96 \%)$; (b) NBS, DTBMP, THF, $\mathrm{H}_{2} \mathrm{O}, 0{ }^{\circ} \mathrm{C}(86 \%)$. 


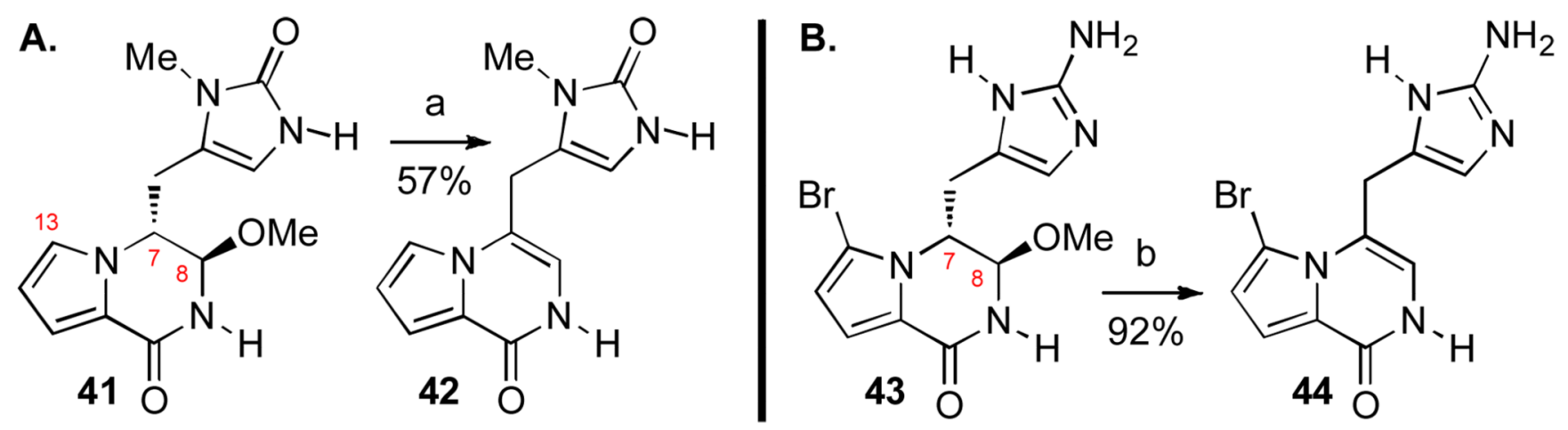

Scheme 5.

Key observations concerning our bioinspired C-ring synthesis strategy. Attempted cyclization of $\mathbf{A}$ ) desbromo-pre-agelastatin A (41) and B) imidazole derivative 43. Reagents and conditions: (a) $\mathrm{MeSO}_{3} \mathrm{H}, \mathrm{H}_{2} \mathrm{O}, 100{ }^{\circ} \mathrm{C}, 20 \min (57 \%)$; (b) Dowex, $\mathrm{H}_{2} \mathrm{O}, 100{ }^{\circ} \mathrm{C}(92 \%)$. 